\title{
VIRAL NATURE OF PAPAYA BUNCHY TOP
}

\author{
By Julio Bird and José Adsuar ${ }^{2}$ \\ INTRODUCTION
}

Attempts to prove that the bunchy top diseave of papaya was transmitted by the leafhopper Empoasca papayae Oman were made by Jensen $(7)^{3}$ who had previously made numerous unsuccessful (fforts to find in and isolate from this host, bacteria, fungi, or protozoa from diseased stems, petioles, and leaves (6). Conclusive evidence that the leafhopper was responsible for the transmission of the causal agent of this disease was presented by Adsuar (1) and later by Sein and Adsuar (8). Transmission of the causal agent by grafting was also obtained (2). Even though the evidence presented by the above-mentioned investigators suggested the possibility of a virus as the causal agent of bunchy top, and although the disease has been successfully controlled by periodic spraying with DDT (3), further investigations were made to determine definitely whether a virus was involved.

It is well known that members of the genus Empoasca cause toxic effects which simulate virus infection in plants. No other host plant of Empoasca papayae has been found in Puerto Rico. All attempts made up to the present to obtain a nonviruliferous insect culture have failed. This led the authors to consider the possibility of the disease being raused by a phytotoxic substance injected by the cicadellid insect.

\section{Experimental Methods and Results}

TRANSMISSION OF THE CAUSAL AGENT BY GRAFTING

Of 30 papaya plants grafted by the junior author (2) with scions from bunchy-top-infected seedlings, 6 developed symptoms of the disease in 2 months, while none of 15 checks became diseased. Although the results of this experiment indicated that the disease was caused by a virus, the evidence was inconclusive, since the experiment did not prove that the causal agent could multiply within the host plant. Side grafting in series was undertaken to determine whether the causal agent is capable of reproducing in the host plant.

\footnotetext{
${ }^{1}$ Presented at the Forty-Third Annual Meeting of 1 he American Phytopathological Society, on December 10th, 1951, at Cincinnati, Ohis.

2 Assistant in Plant Pathology, and Plant Pathologist respectively, Department of Plant Pathology, Agricultural Experiment Station, University of Puerto Rico, Río Piedras, P.R. The help of Dr. George N. Wolcott, I)r. Lindsay M. Black and Dr. Francis $\mathrm{O}$. Holmes is gratefully acknowledged.

${ }^{3}$ Numerals in parentheses refer to Literature Cited, p. 11.
} 
The first group to be grafted comprised 25 healthy, potted papaya plants about 4 months of age. Infected scions were obtained from the tops of diseased plants kept in the greenhouse which showed typical bunchy top symptoms. Infected scions were grafted about 3 inches below the apex of healthy plants and the grafts were secured with Horselastic ${ }^{4}$ tape. After 6 days the tape was removed. By this time the scions had firmly adhered to the stocks. These grafted plants and others used in subsequent tests were kept in a greenhouse with a high relative humidity and at a temperature fluctuating between $78^{\circ}$ and $100^{\circ} \mathrm{F}$ : Twenty-five healthy papaya plants were used as controls. Every 10 days after treatment, all plants, both treated and controls, were pricked from the top down with an insect pin and observations were made for latex flow, the absence of which is a most striking characteristic of the disease.

In general, from 25 to 45 days after grafting, the top of the healthy stocks started to develop symptoms of bunchy top. About 1 week before the appearance of typical bunchy top symptoms in the grafted plants, their tops failed to exude latex when pricked. In no case were such symptoms noticed on the controls. At the end of $1 \frac{1}{2}$ months typical bunchy top symptoms were present in the tops of grafted plants, i.e., failure of latex to flow, rigidity of affected leaves and petioles, presence of oily spots in 'upper part of stem and petioles, and the tendency of the petioles to assume a more or less horizontal position, giving an umbrellalike appearance to the plant (fig. 1). Upon cutting the petioles transversely it was found that the natural central hollow cavity was filled with tissue. The stems were brittle above the grafts and,'when sectioned, a brownish discoloration was observed. None of the 25 controls developed such symptoms.

The disease was transmitted by grafting in series 7 times after the first successful attempt, using 15 plants in each of the 7 experimental series, and 15 checks. A total of 130 plants was successfully infected by grafting while none of an equal number of checks developed the disease.

It was interesting to observe that, after the disease developed, the portion of the stem below the grafted area would exude latex on being punctured with an insect pin. Since failure of latex to flow on pricking is the first and most reliable indication that infection has occurred, it appeared probable that invasion of tissues by the caisal agent was shortly or immediately followed by cessation of latex flow from them. As will be seen later, this assumption was corroborated.

NUMBER OF INSECTS NEEDED TO TRANSMIT BUNCHY TOP IN HEALTHY PLANTS

In an attempt to gather more data on the transmission of .bunchy top by the leafhopper vector, and to establish the viral nature of the disease,

${ }^{4}$ Horselastic cohesive race-horse leg wrap, manufactured by Surgical Dressings, Inc., Boston, Mass. 
it seemed important to determine the smallest number of insects required to produce bunchy top symptoms in papaya. If bunchy top is caused by a virus, a single viruliferous insect should be able to cause the disease. Of course, smaller numbers of successful inoculations are to be expected when. using single insects.

In general, the papaya seedlings used in this experiment were about 12 inches tall. The top growths of such seedlings were enclosed in cellophane bags in which adult insects were released to feed. Leafhoppers were collected from bunchy-top-affected trees and fed on diseased tissue for 1 day before being released in the cellophane bags. They were left in the cellophane bags

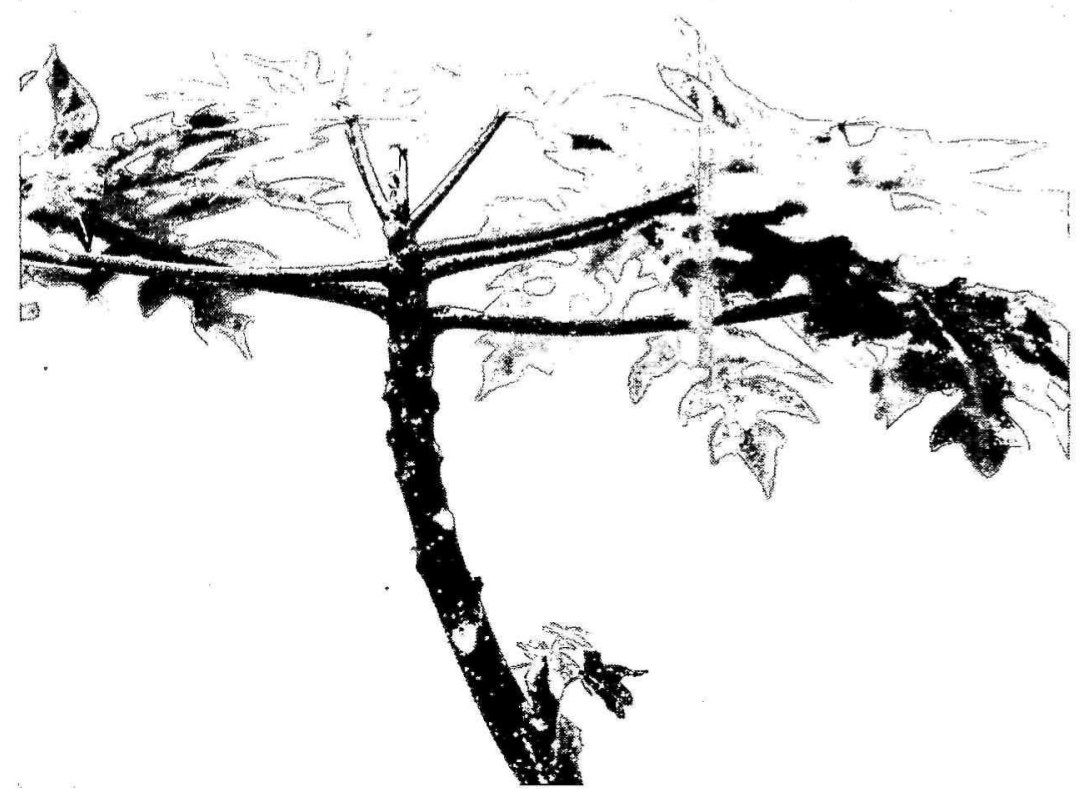

Frg. 1.-Typical bunchy top symptoms in a young papaya tree as a result of grafting with a diseased scion.

for 1 day, although many died during the first ferv hours. After their allotted feeding time the surviving insects were killed. Each treated plant was paired with one healthy untreated control. At the end of $1 \frac{1}{2}$ months, observations were made. Table 1 shorvs the results of this experiment.

It is obvious from table 1 that some individual insects are capable of transmitting the causal agent. In the first test only 1 plant developed the disease when a single insect was used. However, in the second test 25 percent of the plants were successfully inoculated using single individuals. It was unfortunate that the number of insects available did not permit extending the test up to 7 individuals per plant. None of the plants became 
infected in test No. III regardless of the number of insects released on them. Because so very little is known about the insect-virus relationship, the writers cannot offer any explanation for the low infection incidence in tests Nos. I and III.

\section{MOVEMENT OF THE CAUSAL AGENT}

Frequent cures of bunchy-top-affected plants by cutting away the diseased tops of the plants were obtained by Jensen (6).

In Trinidad, Baker (4) studied a mosaic disease of papaya resembling bunchy top, in which natural recovery was possible. It was characterized by profuse development of healthy axillary branches and by the loss of the

TABLE 1.-Number of successful inoculations of healthy papaya plants by leafhoppers, in numbers varying from 1-7 individuals per plant

\begin{tabular}{|c|c|c|c|}
\hline Test No. & Insects per plant & $\frac{\text { Plants infected }}{\text { Plants inoculated }}$ & $\frac{\text { Plants infected }}{\text { Uninoculated plants }}$ \\
\hline \multirow{8}{*}{ I } & Number & Number & Number \\
\hline & 1 & $1 / 29$ & $0 / 29$ \\
\hline & 2 & $1 / 9$ & $0 / 9$ \\
\hline & 3 & $0 / 11$ & $0 / 11$ \\
\hline & 4 & $0 / 11$ & $0 / 11$ \\
\hline & 5 & $1 / 10$ & $0 / 10$ \\
\hline & 6 & $2 / 10$ & $0 / 10$ \\
\hline & 7 & $2 / 10$ & $0 / 10$ \\
\hline II & 1 & $5 / 20$ & $0 / 20$ \\
\hline \multirow[t]{7}{*}{ III } & 1 & $0 / 30$ & $0 / 30$ \\
\hline & 2 & $0 / 10$ & $0 / 10$ \\
\hline & 3 & $0 / 10$ & $0 / 10$ \\
\hline & 4 & $0 / 10$ & $0 / 10$ \\
\hline & 5 & $0 / 10$ & $0 / 10$ \\
\hline & 6 & $0 / 10$ & $0 / 10$ \\
\hline & 7 & $0 / 10$ & $0 / 10$ \\
\hline
\end{tabular}

leading infected shoot. Baker observed that die-back of the crown is possibly more rapid than the downward spread of the virus. Jensen (5) found that the ringspot virus of papaya had a relatively slow rate of downward spread. Results obtained by these investigators working with papaya virus diseases indicated that some papaya viruses had a slow rate of downward spread.

Since little work had been done on the downward movement of the causal agent of bunchy top, the following observations were made:

As was mentioned earlier, $1 \frac{1}{2}$ months after grafting failure of latex to flow was restricted to the part of the stem above the lower end of the scion. In preliminary tests it was found that if the stem was severed at the level where 
latex still onzed on pricking, the diseased area could be eliminated and only healthy shcots emerged from the treated stem. This did not occur when the stem was severed at heights where latex failed to flow on tapping. In these last instances diseased shoots developed from the part of the stem where latex failed to emerge on pricking. Since this was evidence that penetration of tissues by the causal agent was soon or immediately followed by cessation of latex flow, further studies were undertaken.

Thirty plants 6 to 8 months old that had shown typical bunchy top symptoms for at least $3 \frac{1}{2}$ months were isolated in an insect-proof greenhouse. Thirty healthy controls of about the same age were placed together with the first group. Both groups were sprayed with wettable DDT ${ }^{5}$ every 15 days. The stems of the infected plants were tapped starting at the top and continuing downwards until latex oozed. This latex-flow level was marked off with red wax. After 6 months 2 of the affected trees had produced healthy axillary shoots at and below the marked point. The leading infected shoot of these 2 trees died back down to the wax-marked area which coincided with a node and were neatly sloughed off. The rest of the infected trees did not "recover" from the disease, their growth was stunted, and only a few leaves remained at their tops. In none of these cases did the disease spread downwards from the marked area, as determined by free flow of latex on pricking. All the controls remained healthy. The results of this experiment showed that no downward spread of the causal agent could be detected after 6 months, while all tissues produced by the plants above the marked area were diseased.

In an attempt to verify previous observations on the downward spread of the causal agent, 20 infected plants chosen $1 \frac{1}{2}$ months after they were grafted with infected scions, were selected at random and the exact level of latex flow was determined. This line of demarcation was very sharp and coincided with the lowermost point in the stem where the scion graft was attached. None of the stems of these infected plants exuded latex on tapping above the level of the lower end of the scion; however, latex flowed freely immediately (within $1 \mathrm{~mm}$.) below this level in all plants.

After 5 months the plants were tapped to determine whether there had been any downward movement of the causal agent. The downward penetration of the stems by the causal agent averaged 1.5 inches below the original line of demarcation. In 4 plants no downward movement at all appeared to occur. However, the downward dispersion of the latex-flow level measured as much as $3 \frac{1}{2}$ inches in one of the plants.

CUTTING BACK AFFECTED TREES AS A CONTROL MEASURE

Since evidence indicated that the causal agent of bunchy top moved rapidly acropetally, while its basipetal spread was very slow, the authors

${ }^{5}$ At a rate of $2 \mathrm{lbs}$. of 50 -percent wettable DDT per 100 gals. of water. 
attempted to restore affected trees to producing capacity by cutting back' the stems to eliminate diseased areas.

Forty-six bunchy-top-affected trees having an average height of 4 feet were divided into 3 groups as follows:

First group (22 plants)-The stems were topped at the highest point where latex flow occurred.

Second group (12 plants)-The stems were topped in the section where no latex flow occurred, that is, above the demarcation line.

Third group (12 plants) - These plants were not topped.

These plants were placed in a greenhouse among 25 healthy plants and all were sprayed every 15 days with DDT.. All the plants of the first group were healthy at the end of 5 months while none of the plants of the second group were cured of the disease. All the plants of the third group remained diseased and none of the healthy controls became infected.

The results of these experiments clearly demonstrated that diseased trees can be restored to health and productivity by cutting back below the affected area of the stem as determined by tapping and observing the latex flow. In further tests it was found that plants will produce healthy shoots if the infected stems can be severed at exactly the point where latex begins to ooze on tapping. If the stems of infected plants are cut back a little above the level where latex appears on pricking, diseased tissue may remain and shoots produced at that point will be diseased. After infected trees are topped, several shoots are produced at various positions along the stem. The topmost lateral shoot should be retained and the remainder excised, as a single shoot will eventually grow to be as thick as the stem supporting it. If all the lateral branches are left, their growth will be spindly.

Six of the trees restored by cutting back the stem as explained above were transplanted into the soil inside an insectproof greenhouse and observed until fruit was produced; they were normal in every respect.

Restoration of affected papaya trees by topping under field conditions has also been attempted and results have been encouraging. Further work is needed to determine whether the yield of trees so treated is affected.

\section{DisCUSSION}

Evidence here presented strongly indicates that the bunchy top disease of papaya is caused by a virus. The strongest evidence was obtained by successive transmission of the causal agent in a series of grafted plants. Plants infected in the seventh transfer of the series developed symptoms as severe as those of plants from which the first diseased scions were obtained. Had a toxin been the causal agent symptoms would have been less severe because the toxin would have become diluted in its passage through one plant after another.

Evidence obtained by the use of the leafhopper Empoasca papayae also 
indicates that a virus is responsible for the disease. A single insect feeding for a period of 24 hours was found capable of transmitting the etiologic agent. Again, if a toxin were the causal agent of papaya bunchy top, the symptoms should be less severe when produced by one insect feeding for 1 day than when several insects fed for the same length of time.

Since the virus moves very slowly downwards through the stem, infected trees can be restored to productivity by cutting back the affected areas. Infected portions can be determined since, as indicated by pricking, latex fails to flow from them. Even though spraying with DDT is an effective control measure for the insect vector in the field some insects can and often do gain access to the plantation and inoculate a few trees. In commercial practice, trees thus infected may be eradicated and replaced with seedlings. It is suggested that, if only a few trees in a field become diseased, they may be cured by topping as described previously. Since no large-scale studies have been made on topping under field conditions, the authors refrain from recommending this procedure as a general practice.

Further studies are needed to determine how topping affects the yield of the trees topped.

\section{Summary}

1. The causal agent of bunchy top can be transmitted by grafting successively in series, thus proving that the etiologic agent can multiply within the host plant, and fortifying the view that the causal agent is a virus.

2. A single insect is capable of transmitting the causal agent; this also indicates that the disease is caused by a virus.

3. Movement, of the virus is rapid in an acropetal, but very slow in a basipetal direction.

4. Because of the slow rate at which the causal agent spreads downward, cutting back of trees below the affected portions has proved to be a means of restoring them to normality and productivity.

\section{Literature Cited}

1. Adsuar, J., Transmission of papaya bunchy top!by a leafhopper of the genus Empoasca, Science 103 316, 1946.

2. - Unpublished data.

3. Adsuar, J., and Martorell, L. F., unpublished data.

4. Baker, R. E. D., Papaw mosaic disease, Trop. Agr. (Trinidad) 16 159-163, 1939.

5. Jensen, D. D., Viruses of papaya, Phytopath 39 191-211, 1949.

6. Jensen, J. H., Studies of papaya bunchy top, Rept. Puerto Rico Exp. Sta. (Federal) for 1937 82-87, 1938.

7. - Papaya bunchy top studies, Rept. Puerto Rico Exp. Sta. (Federal) for 1938 121-125, 1939.

8. Sein, F., and J. Adsuar, Transmission of the bunchy top disease of papaya (Carica papaya L.) by the leafhopper Empoasca papayae Oman, Science 106 130, 1947. 